\title{
Engineering Solid-State Porosity of Synthetic Supercontainers via Modification of Exo-Cavities
}

Li-Ji Cheng, ${ }^{[a, b]}$ Xin-Xia Fan, ${ }^{[a, b]}$ Yi-Peng Li, ${ }^{[a, b]}$ Qiao-Hua Wei, ${ }^{* a, b]}$ Feng-Rong Dai, ${ }^{[b]}$ ZhongNing Chen, ${ }^{[b]}$ and Zhenqiang Wang ${ }^{[c]}$

\begin{abstract}
Two new coordination supercontainers have been successfully isolated from the self-assembly reactions of the container precursor $p$-phenylsulfonylcalix[4]arene, $\mathrm{Ni}$ (II) or $\mathrm{Co}$ (II) ion, and diphenylmethane-4,4'-dicarboxylic acid. Crystal structure analysis revealed that these two coordination supercontainers possess a similar endo cavity and two deeper exo cavities compared to the related supercontainers based on p-tert-butylsulfonylcalix[4]arene. Gas and vapor adsorption studies indicated that the new compounds are permanently porous and show much better $\mathrm{CO}_{2} / \mathrm{O}_{2}$ and $\mathrm{CO}_{2} / \mathrm{N}_{2}$ selectivity and higher vapor adsorption than the tert-butyl analogues.
\end{abstract}

Keywords: coordination container, sulfonylcalix[4]arene, supramolecular chemistry, gas separation, vapor adsorption

Molecular containers possessing hollow space have received considerable attention in view of their promising applications in a wide array of areas, including stabilization of highly reactive species, transportation of small molecules, gas storage and separation, sensing, supramolecular catalysis and molecular recognition.[1-6] Because of the relatively robust and reversible nature of coordination bonding between metal and ligand, coordination-driven self-assembly affords an excellent means to construct elegant supramolecular architectures containing hollow structures. [7-13] We have focused on the construction of coordination containers featuring unique multiple binding cavities within a single host structure by incorporating sulfonylcalix[4]arenes[14] as container precursors. A new family of coordination containers, namely, metal-organic supercontainers (MOSCs), have been obtained from the assembly of sulfonylcalix[4]arenes, divalent metal ions and carboxylate linkers of trigonal, linear, angular-planar, or angularnonplanar shape.[15-18] The lower rim of sulfonylcalix[4]arenes was bridged by the carboxylate linkers via both binding to the same metal ions to generate four prototypes of MOSCs that possess a characteristic multi-pore architecture, i.e., an endo cavity and multiple exo cavities. Related 
supercontainer structures derived from thiacalix[4]arenes, in place of sulfonylcalix[4]arenes, have also been recently investigated by the research groups of Liao and Hong [19, 20]. While it has been shown that the geometry of the endo cavity can range from face-directed octahedron (type I MOSCs)[15], edge-directed octahedron (type II MOSCs)[16], barrel-shaped box (type III MOSCs)[17], to cylindrical structure (type IV MOSCs)[18], depending on the type of carboxylate linker chosen, we anticipate that the exo cavities can be precisely controlled by the cup-shape configuration[14] of the sulfonylcalix[4]arene units locked in by the metal coordination. Therefore, chemically modifying the para position of the sulfonylcalix[4]arene precursor provides a fruitful strategy to manipulate the exo porosity of the MOSCs [15-19]. Herein, we demonstrate that replacing $p$-tert-butylsulfonylcalix[4]arene (TBSC) used in our previous studies with $p$ phenylsulfonylcalix[4]arene (PSC) [21] in the modification of type IV MOSCs proves effective in engineering their solid-state porosity and gas/vapor adsorption properties. In particular, we show that incorporating extended phenyl groups at the upper rim of the exo cavities not only produces a deeper, $\pi$-electron rich cavity but also allows more substantial $\pi$ - $\pi$ stacking that contribute to maintaining the solid-state packing and structural ordering of the discrete container crystals.

Scheme 1. Assembly of p-phenyl-sulfonylcalix[4]arene based coordination supercontainer. The yellow sphere serves to guide the eyes.

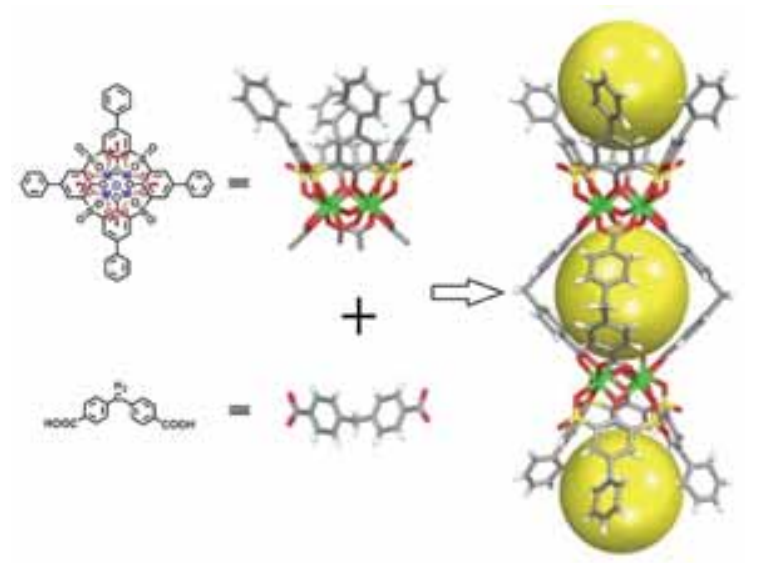

The new supercontainer 1 was isolated as green crystals upon the reaction of $\mathrm{Ni}\left(\mathrm{NO}_{3}\right)_{2} \cdot 6 \mathrm{H}_{2} \mathrm{O}$ with diphenylmethane-4,4'-dicarboxylic acid (H2DPMDC) and p-phenylsulfonylcalix[4]arene ( $\mathrm{H}_{4} \mathrm{PSC}$ ) in DMF at $100^{\circ} \mathrm{C}$ (Scheme 1).[22] The compound was fully characterized by singlecrystal X-ray diffraction (SCXRD), powder X-ray diffraction (PXRD), thermogravimetric analysis (TGA), Fourier transform IR spectroscopy (FTIR), and UV-Vis spectroscopy. The PXRD patterns confirmed the crystallinity and phase purity of the as-synthesis material (Figure 1a). The TGA revealed that compound $\mathbf{1}$ has a thermal stability similar to that of the TBSC-derived MOSCs, featuring a de-composition temperature of above $400{ }^{\circ} \mathrm{C}$ under the nitrogen atmosphere (Figure 1b).[18] The ca. $25 \%$ weight loss before $200{ }^{\circ} \mathrm{C}$ is attributed to the release of solvent molecules (i.e., $N, N$-dimethylformamide, DMF, estimated to be 14 molecules, vide infra) entrapped within the coordination capsule. 

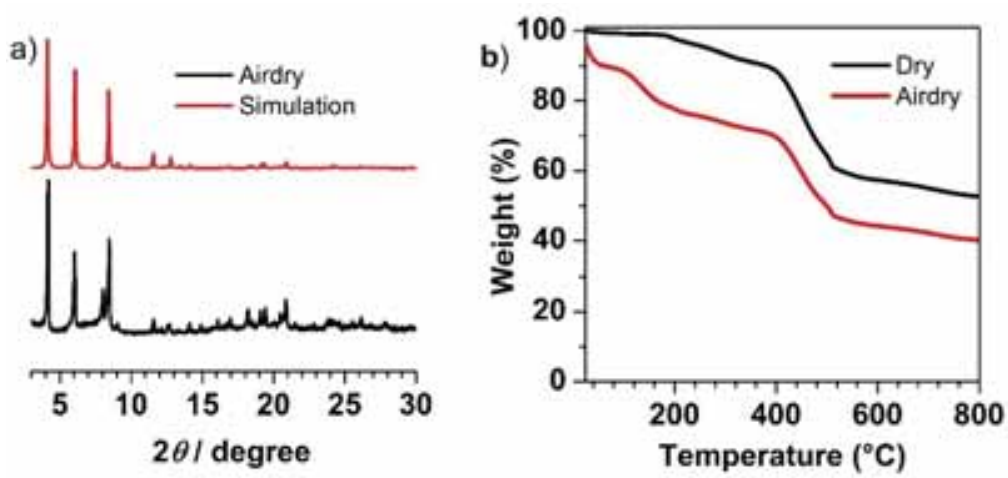

Figure 1. a) Powder X-ray diffraction patterns of $\mathbf{1} ;$ b) TGA of as-synthesized and activated sample of $\mathbf{1}$.

SCXRD studies showed that compound 1 crystallized in the tetragonal crystal system and P4/ mnc space group.[23] The molecular structure of compound $\mathbf{1}$ resembles a cylindrical shape similar to the tert-butyl MOSCs, although it should be noted that $\mathbf{1}$ crystalized in a space group with a much higher symmetry (i.e., $P 4 / m n c$ vs. $P$-1). As shown in Figure 1, two tetranuclear units, each containing a $\mu_{4}$-oxygen species from a presumably neutral water molecule, were bridged by four DPMDC linkers, which adopted the V-shaped geometry with a dihedral angles of $107.8^{\circ}$ between the two benzene rings. 1 exhibits an endo cavity similar to that observed in the TBSC analogue, which is defined by the lower rim of PSC and DPMDC ligands and features a longitudinal diameter of ca. $10 \AA$ and pore openings of ca. $4.6 \AA \times 10 \AA$; however, comparing to the TBSC analogue, 1 possesses two much wider (with an opening of $13 \AA \times 13 \AA$ ) and deeper (with a depth of ca. $8 \AA$ ) cup-shaped exo cavities, defined by the upper rim of PSC. Multiple faceto-face $\pi-\pi$ interactions are found between the aromatic rings of PSC: each PSC formed eight visible $\pi-\pi$ interactions (with a centroid-centroid distance of $3.463 \AA$ ) with four adjacent PSC ligands. As a result, compound $\mathbf{1}$ adopts a less efficient packing mode, namely, pseudo bodycentered cubic (bcc) packing, in solid state, with a total potential solvent-accessible volume of ca. 44.7\% calculated using the PLATON program.[24] The free volume, which includes the enclosed exo and endo cavities and the interstitial space, is presumably occupied with the solvent molecules (i.e. DMF); unfortunately, they are highly disordered and not able to be located by the X-ray crystallography. However, according to the crystallographic analysis, SQUEEZE results, and TG analysis, the empirical formula of compound $\mathbf{1}$ is estimated to be $\left[\mathrm{Ni}_{4}\left(\mu_{4}-\right.\right.$ $\mathrm{H}_{2} \mathrm{O}$ )PSC $]_{2}$ (DPMDC) $)_{4} \cdot 14 \mathrm{DMF}$. Furthermore, an isomorphic crystal of cobalt analogue, namely, compound 2, was also successfully isolated under similar reaction conditions by simply replacing the $\mathrm{Ni}^{2+}$ with $\mathrm{Co}^{2+}$, indicating that the formation of such coordination supercontainers is highly predictable and reliable. 

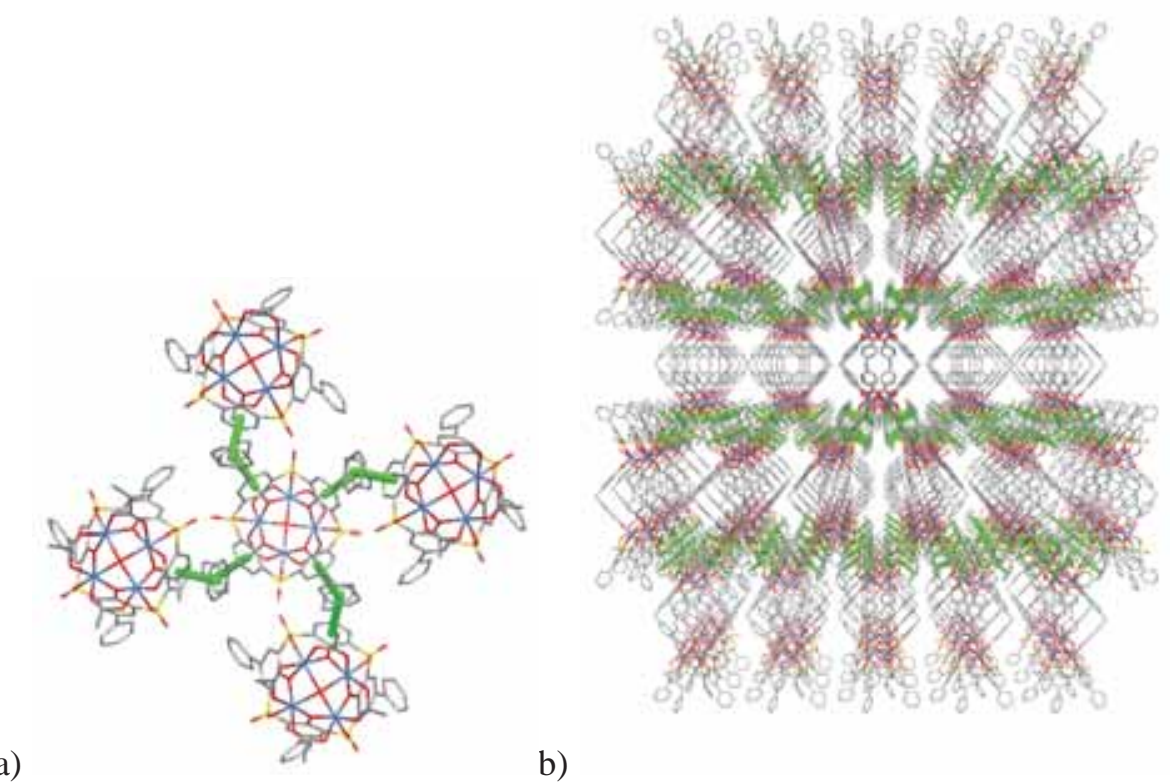

b)

Figure 2. a) Face-to-face $\pi-\pi$ stacking interactions between the aromatic rings from adjacent PSC; b) The 3D packing of $\mathbf{1}$ through $\pi-\pi$ interactions. The hydrogen atoms and solvent molecules are not included.

Preliminary gas/vapor adsorption studies of $\mathbf{1}$ were investigated using the activated sample. Its $\mathrm{N}_{2}$ sorption at $77 \mathrm{~K}$ gave a "pseudo" type I adsorption isotherm which features a small but visible adsorption/desorption hysteresis. It confirmed that compound 1 adsorbs up to $284 \mathrm{~cm}^{3} / \mathrm{g}$ at $77 \mathrm{~K}$ and $1 \mathrm{~atm}$, and has a Brunauer-Emmett-Teller (BET) surface area estimated at $835 \mathrm{~cm}^{2} / \mathrm{g}$. This finding is particularly remarkable when compared to the TBSC analogue, which exhibited essentially negligible $\mathrm{N}_{2}$ uptake at $77 \mathrm{~K}$ and $1 \mathrm{~atm}\left(\sim 10 \mathrm{~cm}^{3} / \mathrm{g}\right.$ STP $)$ and thus nonporous to $\mathrm{N}_{2}$ [18]. This result highlights the profound impact of replacing t-butyl units with the more extended phenyl groups on retaining the crystal packing and solid-state porosity of compound $\mathbf{1}$ even after the removal of its lattice solvents. Additional adsorption studies involving $\mathrm{O}_{2}$ and $\mathrm{H}_{2}$ at $77 \mathrm{~K}, \mathrm{CO}_{2}$ at $196 \mathrm{~K}$ were also carried out, which revealed that compound $\mathbf{1}$ has a persistently higher adsorption capacity than that of the TBSC-based analogue. The apparent $\mathrm{CO}_{2} / \mathrm{O}_{2}$ and $\mathrm{CO}_{2} / \mathrm{N}_{2}$ adsorption selectivity of compound $\mathbf{1}$ at ambient temperature was further established by the examining its affinity with $\mathrm{CO}_{2}, \mathrm{~N}_{2}$, and $\mathrm{O}_{2}$ at $293 \mathrm{~K}$ (Figure $3 \mathrm{~d}$ ). The result indicated its potentially relevant applications in carbon dioxide separation/capture. Moreover, vapor adsorption experiments showed significant uptake of $\mathrm{MeOH}\left(\sim 203 \mathrm{~cm}^{3} / \mathrm{g}\right.$ STP or $\sim 30$ molecules per container) and benzene ( $\sim 113 \mathrm{~cm}^{3} / \mathrm{g}$ STP or $\sim 17$ molecules per container) at $293 \mathrm{~K}$ by compound 1 (Figure 3), both of which double the corresponding adsorption capacity of the TBSC analogue. 

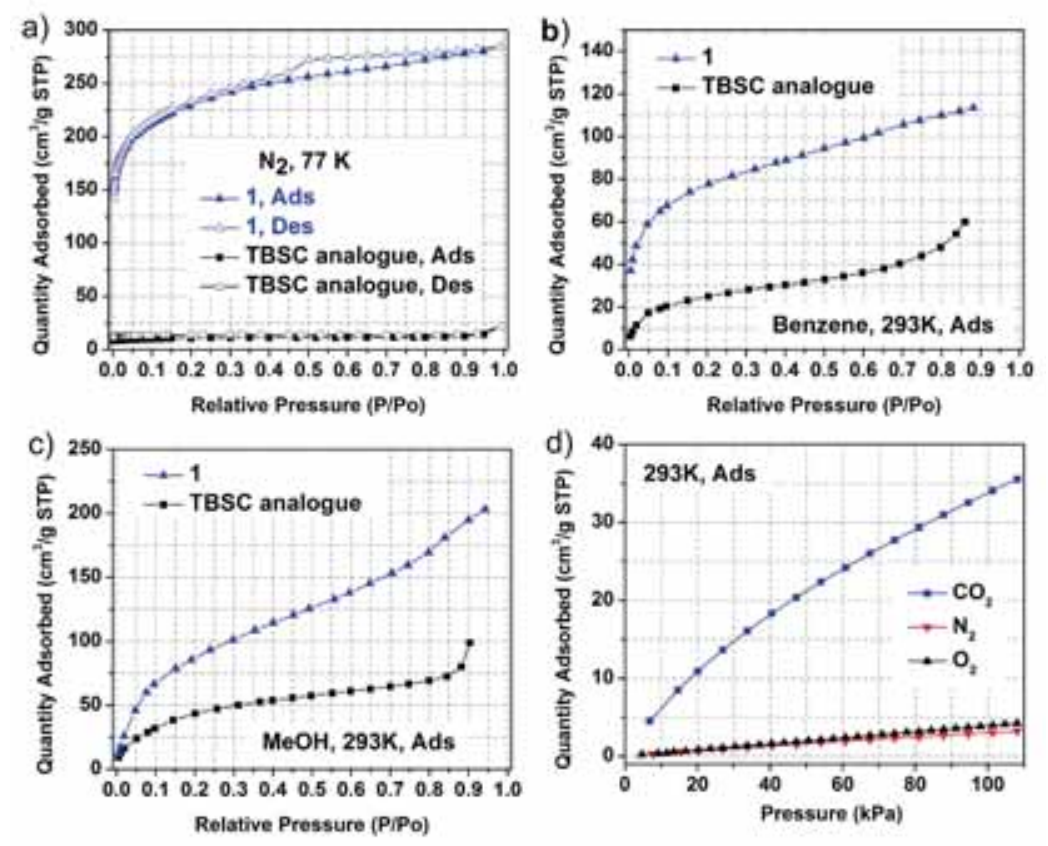

Figure 3. a) $\mathrm{N}_{2}$ (77 K); b) Benzene (293 K); c) MeOH (293 K), and d) $\mathrm{N}_{2}(293 \mathrm{~K}), \mathrm{O}_{2}$ (293 K) and $\mathrm{CO}_{2}(293 \mathrm{~K})$ sorption isotherms of $\mathbf{1}$ by comparing to the TBSC analogue.

In conclusion, two new coordination supercontainers derived from $p$ phenylsulfonylcalix[4]arene have been successfully obtained from the self-assembly reaction. Incorporating the phenyl groups to these new structures represents an effective approach to modifying their exo cavities and overall solid-state porosity. Compared to the p-tertbutylsulfonylcalix[4]arene based analogue, these new supercontainers possess a similar endo cavity but exhibited deeper exo cavities sustained by extended phenyl groups and more extensive $\pi$ - $\pi$ interactions. Thanks to these substantial $\pi-\pi$ interactions, the new supercontainers have a less efficient but more robust crystal packing, giving rise to higher overall porosity and gas/vapor adsorption capacity. Most importantly, these characteristics have led to higher $\mathrm{CO}_{2} / \mathrm{O}_{2}$ and $\mathrm{CO}_{2} / \mathrm{N}_{2}$ adsorption selectivity, indicating the potential applications of these new materials for gas separation.

\section{Acknowledgements}

This work was supported by the NSFC (21501179 and 21673239). Z.W. acknowledges the financial support of a National Science Foundation CAREER Award (CHE-1352279).

\section{Appendix A. Supplementary data}

Structural, spectroscopic, and additional characterizations of the new compounds. Supplementary data to this article can be found online at http://dx.doi.org/10.1016/j.inoche.xxxx.

\section{References}

[1] P. Mal, B. Breiner, K. Rissanen, J.R. Nitschke, White Phosphorus Is Air-Stable Within a SelfAssembled Tetrahedral Capsule, Science, 324 (2009) 1697-1699.

[2] T. Mitra, X. Wu, R. Clowes, J.T.A. Jones, K.E. Jelfs, D.J. Adams, A. Trewin, J. Bacsa, A. Steiner, A.I. Cooper, A Soft Porous Organic Cage Crystal with Complex Gas Sorption Behavior, Chem. Eur. J., 17 (2011) 10235-10240. 
[3] R. Pinalli, E. Dalcanale, Supramolecular Sensing with Phosphonate Cavitands, Acc. Chem. Res., 46 (2013) 399-411.

[4] Y. Qiao, L. Zhang, J. Li, W. Lin, Z. Wang, Switching on Supramolecular Catalysis via Cavity Mediation and Electrostatic Regulation, Angewandte Chemie International Edition, 55 (2016) 12778-12782.

[5] D. Ajami, J. Rebek, Chemical approaches for detection and destruction of nerve agents, Org. Biomol. Chem., 11 (2013) 3936-3942.

[6] S. Turega, M. Whitehead, B.R. Hall, M.F. Haddow, C.A. Hunter, M.D. Ward, Selective guest recognition by a self-assembled paramagnetic cage complex, Chem. Commun., 48 (2012) 2752-2754.

[7] M. Fujita, N. Takeda, K. Umemoto, K. Yamaguchi, A nanometre-sired hexahedral coordination capsule assembled from 24 components, Nature, 398 (1999) 794-796.

[8] R. Chakrabarty, P.S. Mukherjee, P.J. Stang, Supramolecular Coordination: Self-Assembly of Finite Two- and Three-Dimensional Ensembles, Chem. Rev., 111 (2011) 6810-6918.

[9] M.M. Conn, J. Rebek, Self-assembling capsules, Chem. Rev., 97 (1997) 1647-1668.

[10] M. Liu, S.C. Du, Y.F. Bi, W.P. Liao, A tetrahedral coordination cage based on p-tertbutylthiacalix[4]arene and 5-sulfoisophthalic acid, Inorg. Chem. Commun., 41 (2014) 96-99.

[11] J. Ahn, K.H. Park, T.H. Noh, O.-S. Jung, Specific molecular container for dioxane: Ionic metallacyclodimeric palladium(II) complex, Inorg Chem Commun, 14 (2011) 1868-1870.

[12] Y. Jiao, C. He, C.-Y. Duan, M4L4 cerium cages assembled from ligands with lower symmetry as a molecular flask, Inorg Chem Commun, 39 (2014) 147-150.

[13] K.-C. Sham, G. Zheng, Y. Pan, K.-C. Lau, S.-M. Yiu, H.-L. Kwong, A $\Lambda \Lambda \Lambda \Lambda$-M4L6 tetrahedral manganese cage: Stereoselective synthesis and captured anion exchange, Inorg Chem Commun, 24 (2012) 70-72.

[14] N. Morohashi, F. Narumi, N. Iki, T. Hattori, S. Miyano, Thiacalixarenes, Chem. Rev., 106 (2006) 5291-5316.

[15] F.-R. Dai, Z. Wang, Modular Assembly of Metal-Organic Supercontainers Incorporating Sulfonylcalixarenes, J. Am. Chem. Soc., 134 (2012) 8002-8005.

[16] F.-R. Dai, U. Sambasivam, A.J. Hammerstrom, Z. Wang, Synthetic Supercontainers Exhibit Distinct Solution versus Solid State Guest-Binding Behavior J. Am. Chem. Soc., 136 (2014) 7480-7491.

[17] F.-R. Dai, D.C. Becht, Z. Wang, Modulating guest binding in sulfonylcalixarene-based metalorganic supercontainers, Chem. Commun., 50 (2014) 5385-5387.

[18] F.-R. Dai, Y. Qiao, Z. Wang, Designing structurally tunable and functionally versatile synthetic supercontainers, Inorganic Chemistry Frontiers, 3 (2016) 243-249.

[19] M. Liu, W.P. Liao, C.H. Hu, S.C. Du, H.J. Zhang, Calixarene-Based Nanoscale Coordination Cages, Angew. Chem. Int. Ed., 51 (2012) 1585-1588.

[20] K. Xiong, F. Jiang, Y. Gai, D. Yuan, L. Chen, M. Wu, K. Su, M. Hong, Truncated octahedral coordination cage incorporating six tetranuclear-metal building blocks and twelve linear edges, Chem. Sci., 3 (2012) 2321-2325.

[21] P. Lhoták, T. Šmejkal, I. Stibor, J. Havlíček, M. Tkadlecová, H. Petř́ičková, Synthesis of a deepcavity thiacalix[4]arene, Tetrahedron Lett, 44 (2003) 8093-8097.

[22] 1: $\mathrm{Ni}\left(\mathrm{NO}_{3}\right)_{2} \cdot 6 \mathrm{H}_{2} \mathrm{O}(145.5 \mathrm{mg}, 0.50 \mathrm{mmol}), \mathrm{H}_{2} \mathrm{DPMDC}(56.4 \mathrm{mg}, 0.22 \mathrm{mmol})$ and $\mathrm{H}_{4} \mathrm{PSC}(84.9$ $\mathrm{mg}, 0.10 \mathrm{mmol}$ ) were dissolved in $12 \mathrm{~mL}$ of DMF. The solution was then divided into ten dram vials (4 $\mathrm{mL}$ capacity). The vial was placed in a sand bath, which was transferred to a programmable oven and heated at a rate of $0.5^{\circ} \mathrm{C} / \mathrm{min}$ from 35 to $100^{\circ} \mathrm{C}$. The temperature was held at $100{ }^{\circ} \mathrm{C}$ for $24 \mathrm{~h}$ before the oven was cooled at a rate of $0.2{ }^{\circ} \mathrm{C} / \mathrm{min}$ to a final temperature of $35^{\circ} \mathrm{C}$. Green crystals of $\mathbf{1}$ were isolated by washing with methanol and dried in the air to give $50.2 \mathrm{mg}$ of the as-synthesized material. 2: The preparation of compound 2 was similar to that of $\mathbf{1}$ except that $\mathrm{Co}\left(\mathrm{NO}_{3}\right)_{2} \cdot 6 \mathrm{H}_{2} \mathrm{O}$ was used instead of $\mathrm{Ni}\left(\mathrm{NO}_{3}\right)_{2} \cdot 6 \mathrm{H}_{2} \mathrm{O}$.

[23] Crystal data for $1: \mathrm{C}_{156} \mathrm{H}_{100} \mathrm{Ni}_{8} \mathrm{O}_{42} \mathrm{~S}_{8}, M r=3372.51$, Tetragonal, $P 4 / \mathrm{mnc}, a=15.4910(10) \AA, b=$ $15.4910(10) \AA, c=42.256(5) \AA, V=10140.3(18) \AA^{3}, Z=2, D_{\mathrm{c}}=1.105 \mathrm{~g} \cdot \mathrm{cm}^{-3}, \mu=0.869 \mathrm{~mm}^{-1}, F(000)$ $=3448, G O O F=1.099$. A total of 35812 reflections were collected, 1458 of which were unique $\left(R_{\text {int }}=\right.$ $0.0626) . R_{1} / w R_{2}=0.0740 / 0.2181$ for 244 parameters and 1458 reflections $(I>2 \sigma(I))$.

Crystal data for 2: $\mathrm{C}_{156} \mathrm{H}_{100} \mathrm{Co}_{8} \mathrm{O}_{42} \mathrm{~S}_{8}, M \mathrm{r}=3374.27$, Tetragonal, $P 4 / \mathrm{mnc}, a=15.4705(9) \AA, b=$ $15.4705(9) \AA, c=42.773(5) \AA, V=10237.3(17) \AA^{3}, Z=2, D_{\mathrm{c}}=1.095 \mathrm{~g} \cdot \mathrm{cm}^{-3}, \mu=0.773 \mathrm{~mm}^{-1}, F(000)$ $=3432, G O O F=1.089$. A total of 39648 reflections were collected, 1657 of which were unique $\left(R_{\mathrm{int}}=\right.$ $0.0523) . R_{1} / w R_{2}=0.0862 / 0.2448$ for 217 parameters and 1657 reflections $(I>2 \sigma(I))$.

$\mathrm{X}$-ray single-crystal diffraction data were collected at $100 \mathrm{~K}$ using graphite-monochromated Mo-K $\alpha$ radiation $(\lambda=0.71073 \AA)$ on a Bruker CCD APEXII diffractometer. The collected frames were processed with the software SAINT. The data were corrected for absorption using the SADABS program. The structure was solved by the Direct methods (SHELX97) in conjunction with standard difference Fourier techniques and subsequently refined by full-matrix least-squares analyses on $F^{2}$. Hydrogen atoms were generated in their idealized positions and all non-hydrogen atoms were refined 
anisotropically. The electron count due to disordering solvents in the void space was calculated using the program SQUEEZE in PLATON software package.

[24] A.L. Spek, Single-crystal structure validation with the program PLATON, J. Appl. Cryst., 36 (2003) 7-13. 